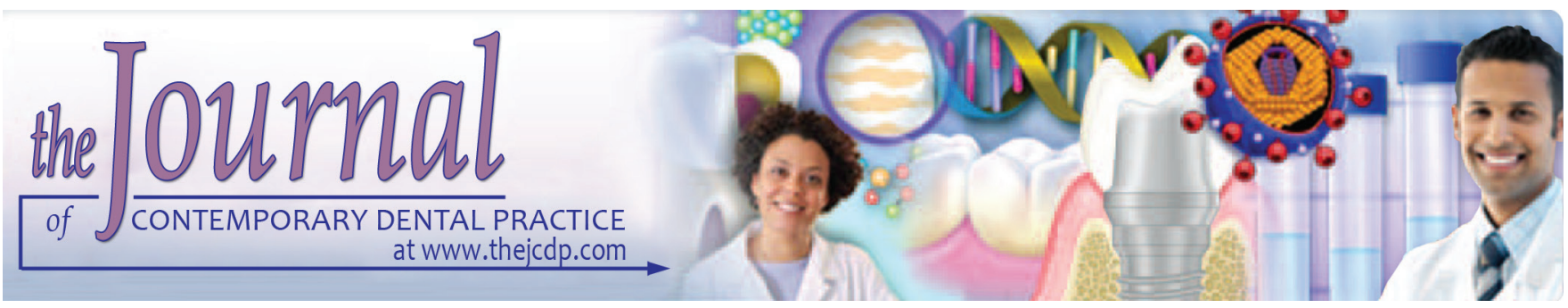

\title{
Early Screening of Diabetes and Hypertension in Primary Care Dental Clinics at King Saud University in Riyadh, Kingdom of Saudi Arabia
}

${ }^{1}$ Emad M Hadlaq, ${ }^{2}$ Ziyad T Faraj, ${ }^{3}$ Fahad M Al Gamdi, ${ }^{4}$ Faisal A Al Obathani, ${ }^{5}$ Mashael F Abuabat, ${ }^{6}$ Kamran H Awan

\begin{abstract}
Introduction: Diabetes mellitus and hypertension are the leading chronic diseases in Saudi Arabia; $23.1 \%$ of the Saudi population are diabetic and $25.5 \%$ are hypertensive. This cross-sectional study was made on dental setting to determine the effectiveness of screening of diabetes and hypertension in dental clinics.

Materials and methods: This study was carried out in the primary care dental clinics at the Dental College in King Saud University in Riyadh, Saudi Arabia. Before starting any treatment, a face-to-face interview was administered to collect a brief medical history and personal data followed by measurement of body mass index (BMI). After that, blood pressure level reading was obtained using electrical sphygmomanometer. Finally, a glucose level reading was obtained from capillary blood from the patient's third fingertip using glucose reader.
\end{abstract}

Results: Our study included 283 participants, 118 of whom were females $(41.7 \%)$. Our study showed that a significant amount of the participants are at risk of having hypertension (44.8\%). In addition, a significant number $(10.2 \%)$ of the participants are at risk of having diabetes. Furthermore, $35.7 \%$ of the sample had obesity as a risk factor for diabetes and hypertension.

Conclusion: The dental team can play an important role in screening of diabetes, hypertension, and other chronic diseases. In Saudi Arabia, public awareness of the chronic diseases is still critically insufficient.

\footnotetext{
${ }^{1-5}$ Department of Oral Medicine and Diagnostic Sciences College of Dentistry, King Saud University, Riyadh, Kingdom of Saudi Arabia

${ }^{6}$ Department of Oral Medicine and Diagnostic Sciences, College of Dentistry, King Saud University, Riyadh, Kingdom of Saudi Arabia; College of Dental Medicine, Roseman University of Health Sciences, South Jordan, Utah, USA

Corresponding Author: Kamran H Awan, Department of Oral Medicine and Diagnostic Sciences, College of Dentistry, King Saud University, Riyadh, Kingdom of Saudi Arabia; College of Dental Medicine, Roseman University of Health Sciences South Jordan, Utah, USA, Phone: +18018781099, e-mail: kamranhabibawan@gmail.com
}

Clinical significance: Our study showed the importance of the screening even for patients with negative history of diabetes or hypertension.

Keywords: Body mass index, Dental clinic, Diabetes mellitus, Early screening, High blood pressure.

How to cite this article: Hadlaq EM, Faraj ZT, Al Gamdi FM, Al Obathani FA, Abuabat MF, Awan KH. Early Screening of Diabetes and Hypertension in Primary Care Dental Clinics at King Saud University in Riyadh, Kingdom of Saudi Arabia. J Contemp Dent Pract 2017;18(8):652-659.

Source of Support: Nil

Conflict of Interest: None

\section{INTRODUCTION}

Diabetes mellitus is "a chronic disease, which occurs when the pancreas does not produce enough insulin, or when the body cannot effectively use the insulin it produces". This leads to an increased concentration of glucose in the blood (hyperglycemia). ${ }^{1}$ There are two types of diabetes: Type I diabetes which develops during childhood and is genetic and type II diabetes which usually develops in adults and is related to obesity, lack of physical activity, and unhealthy diet. Type II diabetes represents about $90 \%$ of the diabetes cases worldwide. ${ }^{1}$

The World Health Organization (WHO) reported that 1 out of 10 adults have diabetes; however, in Saudi Arabia, the ratio is one out of four adults. ${ }^{2}$ Undiagnosed and untreated diabetes will increase the morbidity and mortality of the disease. The WHO reported that about 1.5 million deaths per year are caused by diabetes worldwide. ${ }^{1}$ Previous study in 2011 in Saudi Arabia showed that $23.1 \%$ of the adults have diabetes. ${ }^{3}$

Diabetes could affect the oral cavity in many ways, such as altered and poor wound healing, increased incidence of bacterial infection, candida infection, xerostomia, 
and salivary gland enlargement. ${ }^{4}$ Furthermore, it is considered as a risk factor for gingivitis and periodontitis.

Hypertension is "a condition in which the blood vessels have persistently raised pressure". Blood pressure is created by the force of blood pushing against the walls of blood vessels (arteries) as the heart pumps it. "The higher the pressure harder the heart has to pump". ${ }^{5}$ Hypertension is considered as one of the most common diseases with high value of mortality and morbidity. ${ }^{6}$ Undiagnosed and untreated hypertension may lead to fatal heart conditions including stroke, aneurysms, coronary artery disease, and kidney disease that may alter dental treatment plan. ${ }^{6}$

Worldwide, about 17 million deaths a year are caused by cardiovascular diseases, of which one-third are caused by complications related to hypertension. ${ }^{6}$ In 2008, about $40 \%$ of the adults above 25 years had hypertension, which translates to about 1 billion people worldwide. Furthermore, it is expected that in the year 2025, the total number will increase by about $24 \%$ in the developed countries and about $80 \%$ in developing countries. ${ }^{7}$

Hypertension is considered the leading risk factor for morbidity and mortality in Saudi Arabia according to the Global Burden of Disease Study. Previous study in 2005 showed that $25.5 \%$ has hypertension and only $44.7 \%$ of them were aware of the disease. ${ }^{8}$

Many studies have shown that overweight individuals have two to six times the risk of being hypertensive. ${ }^{2}$ Furthermore, overweight individuals have five times the risk of diabetes. In Saudi Arabia, obesity is increasing and becoming a more serious health condition; recent study showed that $36.68 \%$ of the Saudi population are overweight and $39.65 \%$ are diagnosed as obese. ${ }^{2}$

Screening for undiagnosed medical condition in dental office is considered a potentially valuable public health service. Determining the efficacy of screening in dental settings is very important to have the acceptance by dental team and the patients. Many studies were done on screening of diabetes and hypertension because of their prevalence in society and the availability of well-validated, safe, and easy-to-use screening tools. ${ }^{9} \mathrm{~A}$ British study found that few dentists screened for high blood pressure, although more than $25 \%$ felt it was a good idea. ${ }^{10}$

Early detection of the chronic condition can save more than $75 \%$ of the total cost of the treatment and decrease the chance of causing deaths by $70 \% .{ }^{9}$ According to the medical expenditure panel survey, only 10 to $20 \%$ of the adults have seen physician yearly, whereas about $40 \%$ of the adults visit the dentist on a yearly basis. ${ }^{9}$ As a result, the dentist may play a major role in early detection and screening of chronic diseases, especially diabetes and hypertension.
A study was done in Jeddah at King Abdulaziz University to determine if screening for blood glucose and blood pressure in dental clinics can play a role in early diagnosis of diabetes and hypertension. ${ }^{2}$ From a sample of 355 patients, $44.8 \%$ had prehypertension, where $22.3 \%$ had stage I hypertension and $6.8 \%$ had stage II hypertension. Furthermore, among 348 patients, $33 \%$ had readings of prediabetes and $1.7 \%$ had readings of diabetes.

Our hypothesis is that there are so many patients with undiagnosed diabetes or hypertension and the dentist can play a main role in screening them. Hence, the purpose of this study was to identify patients who are at risk of developing or having undiagnosed diabetes or hypertension using the dental setting. In addition, we also evaluated the correlation between screening results, lifestyle, and family history of hypertension and diabetes.

\section{MATERIALS AND METHODS}

\section{Study Sample}

This was a cross-sectional study that comprised male and female patients seeking dental treatment from December 2015 to January 2016 at the Dental College in King Saud University. Patients who were 18 years and above, had no reported and diagnosed diabetes and hypertension were included in this study. Patients who had heartor renal-related disorders, using medications, such as nonsteroidal anti-inflammatory drugs, steroids, barbiturates, vitamin B12, and/or had a history of any systemic diseases including diabetes and hypertension were excluded from this study. This study was approved by the Institutional Ethics Committee (College of Dentistry Research Center - IR0164).

\section{Data Collection}

The study was explained to the patients and consent obtained. After obtaining the demographic data (age, gender, brief medical history, family history of diabetes and hypertension), smoking habit of the patients was assessed as either being current smokers, previous smokers, or never smokers.

All the data were collected using self-structured, peer-reviewed, and piloted questionnaire. Patients were given 5 minutes rest before the interview to avoid any false raised respiratory and pulse rate due to anxiety. The interview was done face to face, followed by BMI and blood pressure measurements. The second reading was taken in case of raised blood pressure (after 5 minutes). Blood glucose levels were recorded at the end. All the procedures were carried out by the dentists who were trained and standardized for the procedures. 


\section{Blood Glucose Measurement}

The American Diabetic Association criteria were used to determine hyperglycemia. Last meal was recorded, and in patients who had not eaten for at least 8 hours, fasting glucose criteria were used. Samples for blood glucose analysis were obtained as capillary blood from the patient's third fingertip. The measurement was carried out using Mini Blood Glucose Reader (Terumo Medisafe, Japan). The results were classified as fasting glucose levels (normal $<100 \mathrm{mg} / \mathrm{dL}$, prediabetes 100-126 mg/ $\mathrm{dL}$, diabetic $\geq 126 \mathrm{mg} / \mathrm{dL}$ ); random glucose levels (normal $<140 \mathrm{mg} / \mathrm{dL}$, prediabetes 140-200 mg/dL, diabetic $\geq 200$ $\mathrm{mg} / \mathrm{dL}$ ). Those patients who were found suggestive of diabetes were informed to visit their physicians for confirmation.

\section{Blood Pressure Measuring}

The classification of the blood pressure was done according to the $\mathrm{WHO}$ and the guidelines of the seventh report of the Joint National Committee on Prevention, Detection, Evaluation, and Treatment of High Blood Pressure. ${ }^{11}$ The measurement was carried out using electrical sphygmomanometer (Datascope Accutorr V, Mindary, USA). Blood pressure measurement was carried out while patient's arm should be supported at the level of the heart and an appropriately sized blood pressure cuff must be used. White-coat effect (WCE) is "a high office blood pressure but whereby hypertension may or may not be present outside the office setting." As a result, to detect WCE, the reading of the heart rate was also recorded. If the heart rate was above the normal range (60-100 beats / minutes), ${ }^{12}$ patient was informed that there is no further dental treatment and given a rest for 10 minutes. Then, the second reading was done after making sure the patient is relaxed.

The results were classified as follows: (normal $<120 \mathrm{~mm} \mathrm{Hg}$ systolic or <80 mm Hg diastolic, prehypertension $<120-139 \mathrm{~mm} \mathrm{Hg}$ systolic or $<80-89 \mathrm{~mm} \mathrm{Hg}$ diastolic, stage I hypertension $<140-159$ mm Hg systolic or $<90-99 \mathrm{~mm} \mathrm{Hg}$ diastolic, and stage II hypertension $\geq 160 \mathrm{~mm} \mathrm{Hg}$ systolic or $\geq 100 \mathrm{~mm} \mathrm{Hg}$ diastolic). ${ }^{13}$ Those patients who were found to be suggestive of hypertension were informed to visit their physicians for confirmation.

\section{Body Mass Index}

The BMI was calculated as body weight in kilograms divided by height in square meters. Weight was measured by kilogram and height with meters. The patients are asked to remove shoes and heavy clothing. The patients are classified according to the guidelines of the WHO. A BMI of 18.5 to 24.9 is considered normal, BMI from
25 to 29.9 is considered overweight, and BMI over 30 is considered obese. ${ }^{14}$

\section{Data Analysis}

Data were analyzed using Statistical Package for the Social Science (SPSS Inc., Chicago, Illinois, USA) version 20 software. Summary statistics, such as means, standard deviations (SDs), and confidence intervals were computed with standard parametric methods. Differences between the groups' variables were tested with Student's t-test. In addition, chi-square test was used for establishing group relationships.

\section{RESULTS}

A total of 283 patients participated in this study. The sample comprised $58.5 \%$ male $(n=165)$ and $41.7 \%$ female $(n=118)$. The mean age was 36.6 years with SD of 13.5 years (Table 1$)$.

More than one-third (37.5\%) of the patients reported that they have no family history of diabetes or hypertension, whereas $17.3 \%$ reported family history of hypertension; $21.6 \%$ of participants had a family history of diabetes and $23.7 \%$ reported a family history of both diabetes and hypertension. Majority of the sample population (80.2\%) was nonsmokers, whereas $14.8 \%$ were smokers and $4.5 \%$ were previous smokers. Table 2 shows the results of the study of BMI, hypertension, and diabetes, which are significant.

\section{Body Mass Index}

The mean BMI was $28.1644 \mathrm{~kg} / \mathrm{m}^{2}$ with SD of 6.41 . Less than $10 \%(6.7 \%)$ of the patients were underweight, $26.5 \%$ within normal range, $31.1 \%$ were obese, and $35.7 \%$ were overweight (Table 2). The BMI in the study showed that it has significant relation with increasing of age and marital status.

\section{Hypertension}

Among the sample, 83 patients (69 male and 14 female) were in prehypertensive stage, 34 patients (19 males and 15 females) were in stage I hypertension, and 10 patients (8 males and 2 females) were in stage II hypertension. The remaining 156 patients (55.1\%; 69 males and 87 females) showed normal reading $(55.1 \%)$ of the sample (Tables 2 to 4$)$.

\section{Diabetes Mellitus Type II}

Fasting glucose test was used for 83 patients, whereas randomized glucose test was used with 199 patients. The type of test was determined by the time of the patient's last meal. Only one patient refused to do glucose test so he 
Early Screening of Diabetes and Hypertension in Primary Care Dental Clinics at King Saud University

\begin{tabular}{ll}
\multicolumn{2}{c}{$\begin{array}{c}\text { Table 1: Sociodemographic characteristics and health condition } \\
\text { of study participants }(\mathrm{n}=283)\end{array}$} \\
\hline Characteristics & $n(\%)$ \\
\hline $\begin{array}{l}\text { Age groups (in years) } \\
<26\end{array}$ & $73(25.8)$ \\
$26-35$ & $88(31.1)$ \\
$36-45$ & $47(16.6)$ \\
$46-55$ & $34(12.0)$ \\
$56-65$ & $41(14.5)$ \\
Gender & \\
Male & $165(58.3)$ \\
Female & $118(41.7)$ \\
Marital status & \\
Single & $92(32.5)$ \\
Married and others & $191(67.5)$ \\
Educational level & \\
Elementary & $26(9.2)$ \\
Intermediate & $10(3.5)$ \\
Secondary & $91(32.2)$ \\
University & $156(55.1)$ \\
Family medical condition & \\
None & $106(37.5)$ \\
Hypertension or cardiac diseases & $49(17.3)$ \\
Diabetes & $61(21.6)$ \\
Both & $67(23.7)$ \\
Diabetes & \\
None & $151(53.4)$ \\
Father & $54(19.1)$ \\
Mother & $52(18.4)$ \\
Both & $26(9.2)$ \\
Hypertension & \\
Fone & $168(59.4)$ \\
Mother & $42(14.8)$ \\
Bother & $42(14.8)$ \\
\hline & $31(11.0)$ \\
\hline
\end{tabular}

Table 2: Distribution of BMI, hypertension, and diabetes among the study participants $(n=283)$

\begin{tabular}{ll}
\hline Clinical variables & $n(\%)$ \\
\hline Body mass index & \\
Underweight & $19(6.7)$ \\
Normal & $75(26.5)$ \\
Overweight & $88(31.1)$ \\
Obese & $101(35.7)$ \\
Hypertension & \\
Normal & $156(55.1)$ \\
Prehypertension & $83(29.3)$ \\
Stage I hypertension & $34(12.0)$ \\
Stage II hypertension & $10(3.5)$ \\
Diabetes ( $n=282)$ & \\
Normal & $253(89.7)$ \\
Prediabetes & $20(7.1)$ \\
Diabetes & $9(3.2)$ \\
\hline
\end{tabular}

was excluded from this sample. Among the sample taken, a total of 253 patients $(89.4 \%$; 146 males, 107 females) were found to have normal glucose level. Twenty patients (7.1\%; 14 males and 6 females) were suspected to be in prediabetes stage, and nine patients $(3.2 \% ; 5$ males and 4 females) were considered diabetic (Tables 2 and 5).

\section{DISCUSSION}

Our study, to the best of our knowledge, is the first in Saudi Arabia to cover the medical screening of hypertension and diabetes with its risk factors in dental settings. It is hoped that these findings may be of help in early detection and control of both diseases.

Table 3: Association between study variables and BMI

\begin{tabular}{|c|c|c|c|c|c|c|}
\hline \multirow[b]{2}{*}{ Characteristics } & \multicolumn{4}{|c|}{ Body mass index } & \multirow[b]{2}{*}{$\chi^{2}$-value } & \multirow[b]{2}{*}{$p$-value } \\
\hline & Underweight & Normal & Overweight & Obese & & \\
\hline \multicolumn{7}{|l|}{ Age groups (in years) } \\
\hline$<26$ & $12(16.4)$ & $33(45.2)$ & $14(19.2)$ & $14(19.2)$ & 57.36 & $<0.001^{*}$ \\
\hline $26-35$ & $4(4.5)$ & $25(28.4)$ & $32(36.4)$ & $27(30.7)$ & & \\
\hline $36-45$ & $0(0)$ & $6(12.8)$ & $13(27.7)$ & $28(59.6)$ & & \\
\hline $46-55$ & $3(8.8)$ & $4(11.8)$ & $10(29.4)$ & $17(50)$ & & \\
\hline $56-65$ & $0(0)$ & $7(17.1)$ & $19(46.3)$ & $15(36.6)$ & & \\
\hline \multicolumn{7}{|l|}{ Gender } \\
\hline Male & $10(6.1)$ & $36(21.8)$ & $57(34.5)$ & $62(37.6)$ & 5.44 & 0.142 \\
\hline Female & $9(7.6)$ & $39(33.1)$ & $31(26.3)$ & $39(33.1)$ & & \\
\hline \multicolumn{7}{|l|}{ Marital status } \\
\hline Single & $14(15.2)$ & $37(40.2)$ & $22(23.9)$ & $19(20.7)$ & 35.25 & $<0.001^{*}$ \\
\hline Married and others & $5(2.6)$ & 38 (19.9) & $66(34.6)$ & $82(42.9)$ & & \\
\hline \multicolumn{7}{|l|}{ Educational level } \\
\hline Elementary & $1(3.8)$ & $9(34.6)$ & $6(23.1)$ & $10(38.5)$ & 14.267 & 0.113 \\
\hline Intermediate & $1(10)$ & $2(20)$ & $5(50)$ & $2(20)$ & & \\
\hline Secondary & $9(9.9)$ & $31(34.1)$ & $19(20.9)$ & $32(35.2)$ & & \\
\hline University & $8(51.8)$ & $33(21.2)$ & $58(37.2)$ & $57(36.5)$ & & \\
\hline \multicolumn{7}{|l|}{ Family medical condition } \\
\hline None & $7(6.6)$ & $28(26.4)$ & $40(37.7)$ & $31(29.2)$ & 10.15 & 0.339 \\
\hline Hypertension or cardiac diseases & $6(12.2)$ & $14(28.6)$ & $14(28.6)$ & $15(30.6)$ & & \\
\hline Diabetes & $2(3.3)$ & $18(29.5)$ & $16(26.2)$ & $25(41.0)$ & & \\
\hline Both & $4(6.0)$ & $15(22.4)$ & $18(26.9)$ & $30(44.8)$ & & \\
\hline
\end{tabular}




\begin{tabular}{|c|c|c|c|c|c|c|}
\hline \multicolumn{7}{|l|}{ (Cont'd...) } \\
\hline \multicolumn{7}{|l|}{ History of diabetes } \\
\hline None & $13(8.6)$ & $40(26.5)$ & $55(36.4)$ & $43(28.5)$ & \multirow[t]{4}{*}{14.17} & \multirow[t]{4}{*}{0.117} \\
\hline Father & $4(7.4)$ & $16(29.6)$ & $9(16.7)$ & $25(46.3)$ & & \\
\hline Mother & $0(0)$ & $14(26.9)$ & $18(34.6)$ & $20(38.5)$ & & \\
\hline Both & $2(7.7)$ & $5(19.2)$ & $6(23.1)$ & $13(50)$ & & \\
\hline \multicolumn{7}{|l|}{ History of hypertension } \\
\hline None & $9(5.4)$ & $48(28.6)$ & $54(32.1)$ & 57 (33.9) & \multirow[t]{4}{*}{16.34} & \multirow[t]{4}{*}{0.060} \\
\hline Father & $1(2.4)$ & $15(35.7)$ & $13(31.0)$ & $13(31.0)$ & & \\
\hline Mother & $7(16.7)$ & $6(14.3)$ & $11(26.2)$ & $18(42.9)$ & & \\
\hline Both & $2(6.5)$ & $6(19.4)$ & $10(32.3)$ & $13(41.9)$ & & \\
\hline \multicolumn{7}{|l|}{ History of smoking } \\
\hline Smoker & $5(11.9)$ & $8(19)$ & $9(21.4)$ & $20(47.6)$ & \multirow[t]{3}{*}{7.17} & \multirow[t]{3}{*}{0.305} \\
\hline I was a smoker & $1(7.1)$ & $3(21.4)$ & $4(28.6)$ & $6(42.9)$ & & \\
\hline I am not a smoker & $13(5.7)$ & $64(28.2)$ & $75(33)$ & $75(33)$ & & \\
\hline
\end{tabular}

*Statistically significant

Table 4: Association between study variables and hypertension stages

\begin{tabular}{|c|c|c|c|c|c|c|}
\hline \multirow[b]{2}{*}{ Characteristics } & \multicolumn{4}{|c|}{ Hypertension } & \multirow[b]{2}{*}{$\chi^{2}$-value } & \multirow[b]{2}{*}{$p$-alue } \\
\hline & Normal & Prehypertension & $\begin{array}{l}\text { Stage I } \\
\text { hypertension }\end{array}$ & $\begin{array}{l}\text { Stage II } \\
\text { hypertension }\end{array}$ & & \\
\hline Age groups (in years) & & & & 0 & & \\
\hline$<26$ & $54(74)$ & $14(19.2)$ & $5(6.8)$ & $0(0)$ & 42.60 & $<0.001^{*}$ \\
\hline $26-35$ & $53(60.2)$ & $29(33.0)$ & $4(4.5)$ & $2(2.3)$ & & \\
\hline $36-45$ & $19(40.4)$ & $17(36.2)$ & $10(21.3)$ & $1(2.1)$ & & \\
\hline $46-55$ & $18(52.9)$ & $8(23.5)$ & $6(17.6)$ & $2(5.9)$ & & \\
\hline $56-65$ & $12(29.3)$ & $15(36.6)$ & $9(22.0)$ & $5(12.2)$ & & \\
\hline \multicolumn{7}{|l|}{ Gender } \\
\hline Male & $69(41.8)$ & $69(41.8)$ & $19(11.5)$ & $8(4.8)$ & 35.77 & $<0.001^{*}$ \\
\hline Female & $87(73.7)$ & $14(11.9)$ & $15(12.7)$ & $2(1.7)$ & & \\
\hline \multicolumn{7}{|l|}{ Marital status } \\
\hline Single & $61(66.3)$ & $22(23.9)$ & $7(7.6)$ & $2(2.2)$ & 7.37 & 0.061 \\
\hline Married and others & $95(49.7)$ & $61(31.9)$ & $27(14.1)$ & $8(4.2)$ & & \\
\hline \multicolumn{7}{|l|}{ Educational level } \\
\hline Elementary & $14(53.8)$ & $12(46.2)$ & $0(0)$ & $0(0)$ & 13.207 & 0.153 \\
\hline Intermediate & $4(40)$ & $3(30)$ & $3(30)$ & $0(0)$ & & \\
\hline Secondary & $52(57.1)$ & $26(28.6)$ & $8(8.8)$ & $5(5.5)$ & & \\
\hline University & $86(55.1)$ & $42(26.9)$ & $23(14.7)$ & $5(3.2)$ & & \\
\hline \multicolumn{7}{|l|}{ Family medical condition } \\
\hline None & $51(48.1)$ & $42(39.6)$ & $10(9.4)$ & $3(2.8)$ & 17.24 & $0.045^{*}$ \\
\hline Hypertension or cardiac diseases & $25(51)$ & $13(26.5)$ & $9(18.4)$ & $2(4.1)$ & & \\
\hline Diabetes & $35(57.4)$ & $19(31.1)$ & $6(9.8)$ & $1(1.6)$ & & \\
\hline Both & $45(67.2)$ & $9(13.4)$ & $9(13.4)$ & $4(6.0)$ & & \\
\hline \multicolumn{7}{|l|}{ History of diabetes } \\
\hline None & $72(47.7)$ & $53(35.1)$ & $20(13.2)$ & $6(4)$ & 13.43 & 0.144 \\
\hline Father & $37(68.5)$ & $9(16.7)$ & $6(11.1)$ & $2(3.2)$ & & \\
\hline Mother & $33(63.5)$ & $15(28.8)$ & $4(7.7)$ & $0(0)$ & & \\
\hline Both & $14(53.8)$ & $6(23.1)$ & $4(15.4)$ & $2(7.7)$ & & \\
\hline \multicolumn{7}{|l|}{ History of hypertension } \\
\hline None & $87(51.8)$ & $63(37.5)$ & $15(8.9)$ & $3(1.8)$ & 24.15 & $0.004^{*}$ \\
\hline Father & $24(57.1)$ & $5(11.9)$ & $10(23.8)$ & $3(7.1)$ & & \\
\hline Mother & $27(64.3)$ & $9(21.4)$ & $3(7.1)$ & $3(7.1)$ & & \\
\hline Both & $18(58.1)$ & $6(19.4)$ & $6(19.4)$ & $1(3.2)$ & & \\
\hline \multicolumn{7}{|l|}{ History of smoking } \\
\hline Smoker & $15(35.7)$ & $21(50)$ & $2(4.8)$ & $4(9.5)$ & 18.91 & 0.004 \\
\hline I was a smoker & $8(57.1)$ & $3(21.4)$ & $3(21.4)$ & $0(0)$ & & \\
\hline I am not a smoker & $133(58.6)$ & $59(26)$ & $29(12.8)$ & $6(2.6)$ & & \\
\hline \multicolumn{7}{|l|}{$B M I$} \\
\hline Underweight & $15(78.9)$ & $4(21.1)$ & $0(0)$ & $0(0)$ & 40.297 & $<0.001$ \\
\hline Normal & $59(78.7)$ & $14(18.7)$ & $2(2.7)$ & $0(0)$ & & \\
\hline Overweight & $41(46.6)$ & $30(34.1)$ & $15(17)$ & $2(2.3)$ & & \\
\hline Obese & $41(40.6)$ & $35(34.7)$ & $34(12)$ & $8(7.9)$ & & \\
\hline
\end{tabular}

*Statistically significant 
Table 5: Association between study variables and diabetes

\begin{tabular}{|c|c|c|c|c|c|}
\hline \multirow[b]{2}{*}{ Characteristics } & \multicolumn{3}{|c|}{ Diabetes } & \multirow[b]{2}{*}{$\chi^{2}$-value } & \multirow[b]{2}{*}{$p$-value } \\
\hline & Normal & Prediabetes & Diabetic & & \\
\hline \multicolumn{6}{|l|}{ Age groups (in years) } \\
\hline$<26$ & $70(95.9)$ & $3(4.1)$ & $0(0)$ & 47.12 & $<0.001$ \\
\hline $26-35$ & $84(95.5)$ & $3(3.4)$ & $1(1.1)$ & & \\
\hline $36-45$ & $45(95.7)$ & $1(2.1)$ & $1(2.1)$ & & \\
\hline $46-55$ & $19(57.6)$ & $9(27.3)$ & $5(15.2)$ & & \\
\hline $56-65$ & $35(85.4)$ & $4(9.8)$ & $2(4.9)$ & & \\
\hline \multicolumn{6}{|l|}{ Gender } \\
\hline Male & $146(88.5)$ & $14(8.5)$ & $5(3.0)$ & 1.187 & 0.552 \\
\hline Female & $107(91.5)$ & $6(5.1)$ & $4(3.4)$ & & \\
\hline \multicolumn{6}{|l|}{ Marital status } \\
\hline Single & $87(94.6)$ & $4(4.3)$ & $1(1.1)$ & 3.703 & 0.157 \\
\hline Married and others & $166(87.4)$ & $16(8.4)$ & $8(4.2)$ & & \\
\hline \multicolumn{6}{|l|}{ Educational level } \\
\hline Elementary & $24(92.3)$ & $0(0)$ & $2(7.7)$ & 12.54 & 0.051 \\
\hline Intermediate & $8(80.0)$ & $1(10.0)$ & $1(10.0)$ & & \\
\hline Secondary & $76(84.4)$ & $12(13.3)$ & $2(2.2)$ & & \\
\hline University & $145(92.9)$ & $7(4.5)$ & $4(2.6)$ & & \\
\hline \multicolumn{6}{|l|}{ Family medical condition } \\
\hline None & $100(94.3)$ & $5(4.7)$ & $1(0.9)$ & 14.59 & 0.024 \\
\hline Hypertension or cardiac diseases & $43(89.5)$ & $1(2.1)$ & $4(8.3)$ & & \\
\hline Diabetes & $51(83.6)$ & $9(14.8)$ & $1(1.6)$ & & \\
\hline Both & $59(88.1)$ & $4(7.5)$ & $3(4.5)$ & & \\
\hline \multicolumn{6}{|l|}{ Diabetes } \\
\hline None & $139(92.7)$ & $6(4.0)$ & $5(3.3)$ & 9.29 & 0.16 \\
\hline Father & $45(83.3)$ & $8(14.8)$ & $1(1.9)$ & & \\
\hline Mother & $47(90.4)$ & $4(7.7)$ & $1(1.9)$ & & \\
\hline Both & $22(84.6)$ & $2(7.7)$ & $2(7.7)$ & & \\
\hline \multicolumn{6}{|l|}{ Hypertension } \\
\hline None & $152(90.5)$ & $14(8.3)$ & $2(1.2)$ & 13.25 & 0.39 \\
\hline Father & $41(97.6)$ & $0(0)$ & $1(2.4)$ & & \\
\hline Mother & $33(80.5)$ & $4(9.8)$ & $4(9.8)$ & & \\
\hline Both & $27(87.1)$ & $2(6.5)$ & $2(6.5)$ & & \\
\hline \multicolumn{6}{|l|}{ History of smoking } \\
\hline Smoker & $37(88.1)$ & $2(4.8)$ & $3(7.1)$ & 7.38 & 0.117 \\
\hline I was a smoker & $11(78.6)$ & $3(21.4)$ & $0(0)$ & & \\
\hline I am not a smoker & $205(90.7)$ & $15(6.6)$ & $6(2.7)$ & & \\
\hline \multicolumn{6}{|l|}{ Hypertension } \\
\hline Normal & $141(90.4)$ & $12(7.7)$ & $3(1.9)$ & 7.87 & 0.248 \\
\hline Prehypertension & $75(90.4)$ & $3(3.6)$ & $5(6)$ & & \\
\hline Stage I hypertension & $30(88.2)$ & $3(8.8)$ & $1(2.9)$ & & \\
\hline Stage II hypertension & $7(77.8)$ & $2(22.2)$ & $0(0)$ & & \\
\hline \multicolumn{6}{|l|}{ Body mass index } \\
\hline Underweight & $13(68.4)$ & $3(15.8)$ & $3(15.8)$ & 28.09 & $<0.001$ \\
\hline Normal & $71(94.7)$ & $4(5.3)$ & $0(0)$ & & \\
\hline Overweight & $86(97.7)$ & $0(0)$ & $2(2.3)$ & & \\
\hline Obese & $83(83)$ & $13(13)$ & $4(4.0)$ & & \\
\hline
\end{tabular}

Hypertension is increasing in Saudi Arabia. More than a quarter of the adult population has hypertension. ${ }^{15}$ In our study, we found that a significant number of the participants were at risk of having hypertension (44.8\%). Other study has shown that $55.3 \%$ of the participants are unaware of hypertension and detected that they may have it. ${ }^{6}$ More than half of the participants who had stages I or
II hypertension had a family history of having hypertension with father, mother, or both. This may reflect that lifestyle is one major cause of hypertension; $96.9 \%$ have increasing BMI as a risk factor. A study carried out in 2013 on obesity and its associated factor in Saudi Arabia showed that $71.18 \%$ of the participants who were diagnosed with hypertension were obese. ${ }^{16}$ 


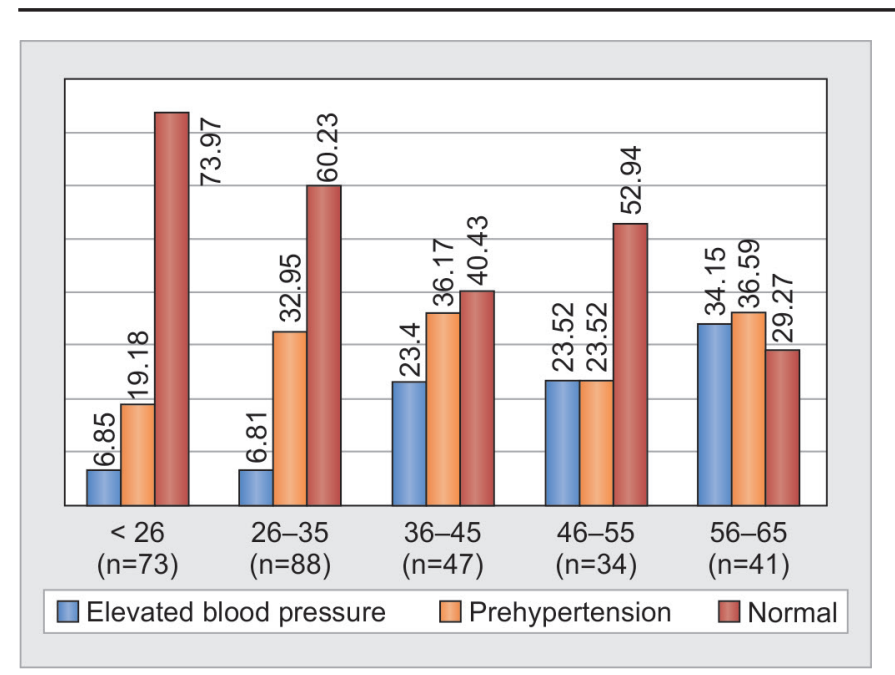

Graph 1: Comparison between blood pressure and age

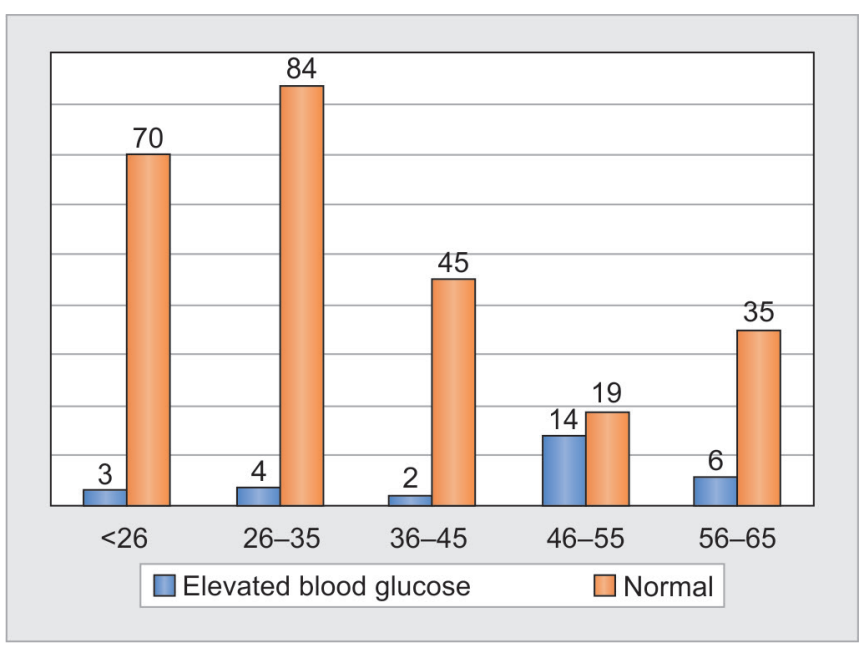

Graph 2: Comparison of glucose level with age
In our study, $10.2 \%$ of the participants were found to be at risk of having diabetes. In a study, authors reported that $21.3 \%$ of the Saudi population in the central region is diabetic. ${ }^{3}$ Another study showed that $27.9 \%$ of undiagnosed participants were at risk of having diabetes. ${ }^{15}$ In our study, $63 \%$ of the participants who were found at risk of having diabetes had a family history of diabetes (father, mother, or both). Moreover, the study showed a significant number of participants $(65.51 \%)$ had obesity as a risk factor. However, in a similar study, only $40 \%$ of the participants were found to be obese. ${ }^{3}$ That might be explained by the larger size of the sample on that study.

Aging is one of the main factors that cause diabetes and hypertension. In our study, we showed significant association between age and the increase of blood pressure and blood glucose level (Graphs 1 and 2). For diabetes, aging induces insulin sensitivity and alters beta-cell function. A previous study showed that between 45 and 64 years, $13.7 \%$ are diabetic. ${ }^{17}$ Increasing thickness of the wall and loss of the elasticity of the arterial walls are the main factors to increase the prevalence of hypertension with age.

Obesity is a major factor causing diabetes, hypertension, and other chronic diseases in Saudi Arabia. In our study, we found that $35.7 \%$ of the sample has obesity as a risk factor; a similar study reported $28.7 \%$ of the Saudi population are obese. ${ }^{16}$ The difference may be explained that the previous study sample included participants 15 years and older, whereas our study included 18 years and older. Our study showed that obesity is increasing with age, a fact that may reflect the lifestyle in our community, which is distinguished by decreased physical activity and high-caloric intake.

Our results suggest a good relation with family history of diabetes or hypertension with having diabetes. Furthermore, lifestyle has strong relation with causing chronic diseases. This condition of having undiagnosed diabetes or hypertension is not occurring only in Saudi
Arabia. In the USA, $15 \%$ of the population had chronic diseases that remained undiagnosed..$^{18}$ It is well known that early detection of diabetes and hypertension greatly helps in reducing the long-term comorbidities and mortalities associated with these conditions. Our study showed that screening of diabetes and hypertension is effective and easy to do in the dental office. We recommend that the screening should be done before the start of dental examination in the waiting area.

This study has a few limitations. The data are crosssectional; as a result, we were not able to assess the causality. This study was carried out in one dental school and therefore, may not reflect the general population. Furthermore, some of the data are self-reported that may be subject to recall and social desirability biases.

\section{CONCLUSION}

The dental team can play an important role in screening of diabetes, hypertension, and other chronic diseases. In Saudi Arabia, the public awareness of the chronic diseases is still critically insufficient. Our study showed the importance of the screening even for patients with a negative history of diabetes or hypertension. Furthermore, this study showed that the dental team could perform and identify the risk factors to help in detection of chronic diseases.

\section{ACKNOWLEDGMENT}

Authors would like to thank the College of Dentistry Research Centre and Deanship of Scientific Research at King Saud University, Saudi Arabia, for supporting this research project.

\section{REFERENCES}

1. World Health Organization. Diabetes. 2013. Available from: http://www.who.int/diabetes/en. 
2. Al-Kayyal MA, Halawani SY, Al-Ghalayini RM, Al-Jefri AY, Al-Hazmi N. Dentists may play a pivotal role in the screening of diabetes and hypertension. Forum 2013 Jan;1(1):44-53.

3. Al-DaghriNM,Al-AttasOS,AlokailMS,AlkharfyKM,YousefM, Sabico SL, Chrousos GP. Diabetes mellitus Type 2 and other chronic non-communicable diseases in the central region, Saudi Arabia (Riyadh cohort 2): a decade of an epidemic. BMC Med 2011 Jun;9:76.

4. Greenberg, M.; Glick, M.; Jonathan, AS. Diabetes mellitus and endocrine diseases. In: Burket's Oral Medicine. Hamilton (ON): BC Decker Inc.; 2008. p. 509-535.

5. World Health Organization. Hypertension. 2013. Available from: http://www.who.int/topics/hypertension/en.

6. World Health Organization. A global brief on hypertension. Vol. 2. Geneva: WHO; 2013.

7. Saeed AA, Al-Hamdan NA, Bahnassy AA, Abdalla AM, Abbas MA, Abuzaid LZ. Prevalence, awareness, treatment, and control of hypertension among Saudi adult population: a national survey. Int J Hypertens 2011 Sep;2011:174135.

8. El Bcheraoui C, Memish ZA, Tuffaha M, Daoud F, Robinson M, JaberS, MikhitarianS, AlSaeedi M, AlMazroa MA, Mokdad AH, et al. Hypertension and its associated risk factors in the Kingdom of Saudi Arabia, 2013: a national survey. Int J Hypertens 2014 Aug;2014:564679.

9. Nasseh K, Greenberg B, Vujicic M, Glick M. The effect of chairside chronic disease screenings by oral health professionals on health care costs. Am J Public Health 2014 Apr;104(4): 744-750.

10. Engström S, Berne C, Gahnberg L, Svärdsudd K. Efficacy of screening for high blood pressure in dental health care. BMC Public Health 2011 Mar;11:194.
11. Chobanian AV, Bakris GL, Black HR, Cushman WC, Green LA, Izzo JL Jr, Jones DW, Materson BJ, Oparil S, Wright JT Jr, et al. The seventh report of the joint national committee on prevention, detection, evaluation, and treatment of high blood pressure: the JNC 7 report. JAMA 2003 May;289(19):2560-2572.

12. All About Heart Rate (Pulse). American heart association. 2015. Available from: http://www.heart.org/HEARTORG/ Conditions / More / MyHeartandStrokeNews / All-AboutHeart-Rate-Pulse_UCM_438850_Article.jsp.

13. World Health Organization. Definition and diagnosis of diabetes mellitus and intermediate hyperglycaemia. Geneva: WHO; 2006.

14. World Health Organization. Obesity and overweight. 2015. Available from: http:/ / www.who.int/mediacentre/factsheets/ fs311/en.

15. Memish ZA, El Bcheraoui C, Tuffaha M, Robinson M, Daoud F, JaberS, MikhitarianS, AlSaeedi M, AlMazroa MA, Mokdad AH, et al. Obesity and associated factors - Kingdom of Saudi Arabia, centers for disease control and prevention. Prev Chronic Dis 2014 Oct;11:E174.

16. Suastika, K.; Dwipayana, P.; Semadi, MS.; Kuswardhani, RA. Age is an important risk factor for type 2 diabetes mellitus and cardiovascular diseases. In: Chackrewarthy S, editor. Glucose tolerance. Indonesia: InTech.; 2012.

17. Al-Nozha MM, Al-Maatouq MA, Al-Mazrou YY, Al-Harthi SS, Arafah MR, Khalil MZ, Khan MB, Al-Khadra A, Al-Marzouki K, Nouh MS, et al. Diabetes mellitus in Saudi Arabia. Saudi Med J 2004 Nov;25(11):1603-1610.

18. Kones R. Is prevention a fantasy, or the future of medicine? A panoramic view of recent data, status, and direction in cardiovascular prevention. Ther Adv Cardiovasc Dis 2011 Feb;5(1):61-81. 